\title{
DC Current Control for a Single-Stage Current Source Inverter in Motor Drive Application
}

\author{
Giovanni Migliazza, Giampaolo Buticchi, Senior Member, IEEE, Emilio Carfagna, Student Member, IEEE, \\ Emilio Lorenzani, Senior Member, IEEE, Vincenzo Madonna, Member, IEEE, Paolo Giangrande, Member, IEEE, \\ and Michael Galea, Senior Member, IEEE
}

\begin{abstract}
The Current Source Inverter (CSI) is a power electronics topology that allows for the realization of variable speed drives (VSD). Compared to the most common Voltage Source Inverter (VSI), which can be directly connected to a voltage source, the CSI needs a pre-stage to generate a constant current bus. This paper therefore seeks to challenge this 'accepted' consideration that a CSI always needs this pre-circuit and seeks to remove this circuit by proposing an innovative $i_{d c}$ Current Control scheme. The proposed scheme is applied to a single stage motor drive driven by a CSI converter. It is shown how implementing this control scheme removes the need for the front-end stage, thus removing an unnecessary converter and optimizing the efficiency at the same time. The CSI state-space equations are presented and the developed models are verified using simulations. Stability analysis of small - signal model is considered through Nyquist criterion with the robustness in presence of variations of the most important system parameters. Experimental results driving a Permanent Magnet Synchronous Machine (PMSM) are shown confirming the validity of the proposed control, potentially paving the way to a larger adoption of the CSI topologies for motor drive applications.
\end{abstract}

Index Terms-Current Source Inverter, DC Current Control, Electric Machine Control, Electric Drive System

\section{INTRODUCTION}

$\mathbf{T}$ HE importance of controlled electric drives (systems that include a power electronic (PE) converter, an electrical machine (EM) and a controller) is well known through all sectors of industry. They facilitate cost effective and efficient renewable energy generation, enable the adoption of more electric aircraft (MEA) technology [1], [2], and provide traction power for electric propulsion in railways [3], ships [4] and cars [5].

Modern, variable speed drives allow for excellent performance in terms of system efficiency, controllability and overall performance. This is of course partially due to the advent of advanced PE converters of the last three decades or so, aided by significant advances in computational technologies.

Known as the work-horse of the industry, the most widespread PE converter for low and medium power (from hundreds of $\mathrm{W}$ to hundreds of $\mathrm{kW}$ ) applications is of course the three-phase full-bridge converter. This simple and robust

G. Migliazza, E. Carfagna and E. Lorenzani are with the Department of Science and Methods for Engineering, University of Modena and Reggio Emilia, Reggio Emilia, Italy

G. Buticchi and M. Galea are with the Key Laboratory of More Electric Aircraft Technology of Zhejiang Province, University of Nottingham Ningbo China, Ningbo 315100, China.

G. Buticchi, V. Madonna, P. Giangrande and M. Galea are with the PEMC Group, University of Nottingham, Nottingham, NG72RD, UK. structure has made the converter the obvious choice for a lot of applications and industries.

In most applications, the inverter stage of the full converter, usually includes a Voltage Source Inverter (VSI) [6]. The advances in the last decades in terms of the development of power semiconductors (IGBT or SiC MOSFETs with no reverse blocking capability) has consolidated the role of the VSI as the most common type of inverter used in converter applications (see [7] and [8]).

A well-known but very rarely implemented alternative to the VSI is the Current Source Inverter (CSI). An authoritative comparison between CSIs and VSIs is given in [9], while [10], [11] study the use of CSIs in photovoltaic applications. The CSI is made up of six bidirectional blocking devices in a full-bridge configuration. Whereas the VSI modulates the DC Link voltage to the output, the CSI modulates the DC Link current, with the obvious advantage of a simple current control, short circuit protection and absence of electrolytic capacitor to form the DC Link. On the other hand, the CSI requires a front-end converter to implement a constant current DC Link. This, combined with the need for bidirectional blocking power devices are the drawback of this topology. Due to these important aspects, the CSI has traditionally been relegated to a secondary role in terms of VSDs and their control.

Recently, however, the need for higher performance systems, especially in terms of power density, efficiency, reliability and robustness is projecting the field of VSDs into a different scenario. The industrial pull represented by initiatives like the MEA [12] and the MEE [5], in their quest towards lighter and greener systems, are demanding ever-higher power density performances [13]. Therefore a lot of research effort is today being focused on higher operational speeds.

Indeed, there are a number of applications, related to transport electrification, where the operating cycle consists of steady state operation with maximum power and maximum speed, and the voltage boosting capability of the CSI is demonstrated to allow for a strong reduction of weight of the machine [14].

Therefore, it is on these considerations that the CSI's role as the $2^{\text {nd }}$ stage of a full bridge converter is perceived to be advantageous. In this context, the well-known drawback of CSIs, namely the input inductor, is immediately mitigated since higher speeds mean higher frequencies, as these automatically result in smaller magnetic components. For a VSI, the higher frequencies only result in minimal variations on the input DC capacitance, which is mostly sized to withstand 
the current ripple. The other main advantage of CSIs is the intrinsic output current control, that automatically removes the associated risks of insulation failure related to high speed voltage control such as high $d V / d t$ s. Therefore, it can be safely stated that for some modern applications and operational conditions, the CSI can be an excellent solution that compares excellently against VSIs.

Having said that, it is however still true that even for higher frequency drives, the CSI still requires a conditioning prestage. It is therefore this particular aspect that this paper seeks to address: the possibility of removing the pre-stage, for application which work constantly at higher operating frequency. If the need for a front-end converter was to be removed, then it is perceived that a much wider acceptance of the CSI in the field of VSDs can be achieved. This paper seeks to achieve this by implementing a new control scheme of the input current, that can replace that need for the converter.

Historically, various solutions aiming to control the input current $i_{d c}$ have been proposed in literature, with most of them revolving around the concept of cancellation and addressing of the harmonic content of the input current. The classical solution for an induction machine (IM) drive is proposed in [15] which comprises two inverter stages, where the first one is a Current Source Rectifier (CSR) that actively controls the $i_{d c}$ current and the second stage is a six-device PWM-CSI. Another methodology for the implementation of a CSI drive is proposed in [16]. The front-end of the CSI is implemented with a buck converter for the DC input voltage. In [17] two different solutions of CSI with front-end converter were proposed. A buck-boost converter and a single-ended primary inductance converter (SEPIC) develop two extended singlestage DC-AC inverters with bidirectional power conversion ability. The solution proposed in [18] uses a DC-DC frontend with 2 additional devices and proposes a two-stage control strategy which guarantees system performance maximization, within the whole operating range. The basic 'message' that can be concluded from all these works is that the conditioning pre-stage for a CSI is essential to allow the output regulation of the converter. A constant $i_{d c}$ current must be guaranteed, for the PWM modulation to work properly. Considering all the above, then it can be concluded that this can be achieved by adopting a control scheme that allows the CSI to operate in boost mode for significant periods of the operation cycle. The purpose of the paper is therefore to propose and validate a new control scheme that allows the implementation of a CSI drive for Permanent Magnet Synchronous Machine (PMSM) without having to rely on a front-end converter. Firstly, a large signal model for the CSI is built and the stability analysis of the system is studied through this model. The proposed scheme is then simulated through a detailed PLECS model. Finally, a regime of experimental work is used to validate the performance of the system. The satisfactory performance of a CSI drive without a pre-conditioning stage is therefore presented.

\section{THEORY OF CSIS}

The schematic of a high efficiency CSI7 is proposed in [19] and shown in Fig. 1. The proposed control scheme of this work is implemented on this CSI in order to highlight the adaptability of the proposed scheme to already-existing hardware. The converter comprises seven reverse blocking switches in a three-phase full-bridge configuration.

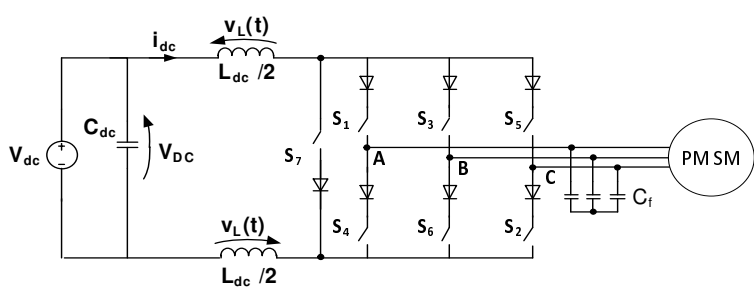

Fig. 1. Schematic of CSI7.

An input inductance constitutes the DC link and output capacitors are used to filter the high frequency output current. During the active states, the operation principle is the same as a VSI, so the input DC current is conditioned by switching and transferred to the output. During the shoot-through state of the CSI (when one or more legs are switched on), the overall voltage over the full-bridge is zero. This configuration takes the name of zero state or null vector.

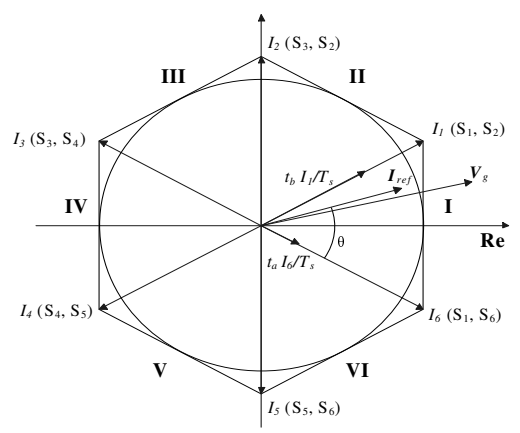

Fig. 2. Space Vector Modulation.

The working principle of the CSI assumes that a constant current source is available. Common passive diodes configurations or other setups that are commonly found in industry cannot guarantee an appropriate current signal. In fact this constant current has always been a defining challenge of the CSI.

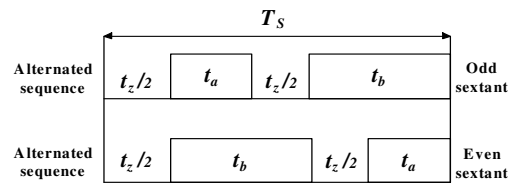

Fig. 3. Alternated Space Vector Modulation.

The CSI operates by chopping the DC current into the output terminals through a PWM scheme. Several modulation strategies have been proposed in literature [20], [21]. The initial step is the definition of the modulation index, which is described by (1), where $\left|i_{\text {ref }}\right|$ is the module of the current space vector and $i_{d c}$ is the DC input current.

$$
m=\frac{\left|i_{r e f}\right|}{i_{d c}}
$$




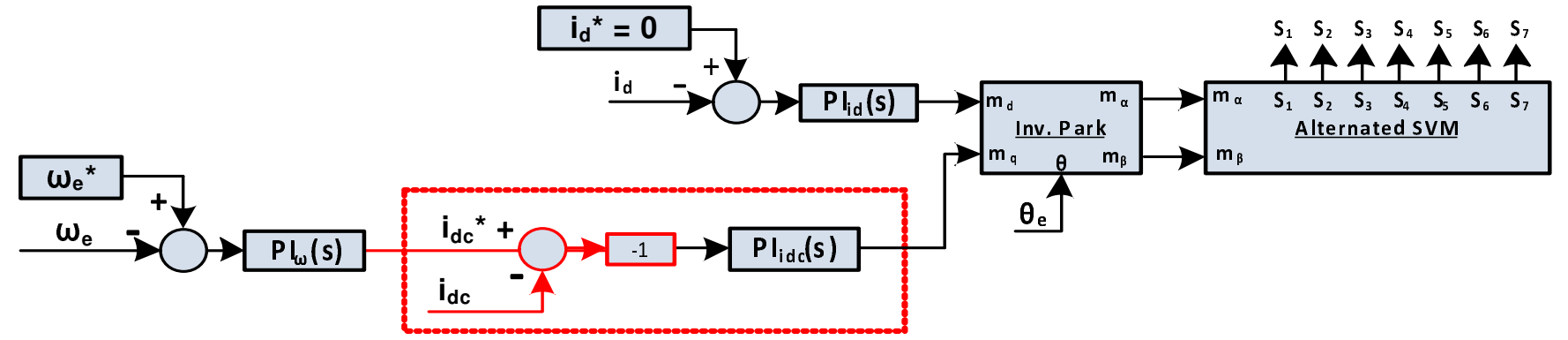

Fig. 4. Proposed control strategy with $i_{d c}$ current control of a PMSM without front-end converter stage.

In Fig. 2, the maximum value of $m$ is $\frac{\sqrt{3}}{2}$, defined by the inner circle of the hexagon and therefore the range of $m$ can be described by (2).

$$
0<m<\frac{\sqrt{3}}{2}
$$

The principle of the SVM is the capability to choose how to synthesize the reference output vector by selecting the best combination of active and zero vectors. During the transition between two vectors, an overlapping time where two vectors are applied simultaneously is introduced to prevent the openload condition that would create an over voltage due to the inductive DC link. This is equivalent to the dead-time for a VSI. To enhance the system operation, it was decided to use an optimized SVM, known as the Alternated Space Vector Modulation, as proposed in [11]. Using this scheme results in better current quality. Figure 3 shows the commutation strategy of the ASVM scheme. In this AVSM, the values of the active states $\mathrm{A} / \mathrm{B}$ are given by $t_{a}$ and $t_{b}$ described by $d_{a} T_{s}$ and $d_{b} T_{s}$, respectively. The time $t_{z}$ of zero state is computed as

$$
t_{z}=T_{s}-\left(t_{a}+t_{b}\right) .
$$

The normalized time intervals of the two active states $d_{a}$ and $d_{b}$ are:

$$
\left\{\begin{array}{l}
d_{a}=\frac{2}{\sqrt{3}} m \sin \left(\frac{\pi}{6}-\theta\right) \\
d_{b}=\frac{2}{\sqrt{3}} m \sin \left(\frac{\pi}{6}+\theta\right)
\end{array}\right.
$$

\section{Proposed Control Strategy}

In this section, the proposed control strategy is introduced. For this work, the structure of the platform being considered is similar to the scheme given in Fig. 1. The control strategy is based on classical Field Oriented Control (FOC), where the novelty is highlighted in the red box in Figure 4.

In most applications requiring VSDs, a stable bus current is not available. However, in transport applications, DC voltage distribution systems are almost always available [22], [23]. Considering all this, then the proposed control scheme can be developed as follows. Firstly, $m$ is defined as $\sqrt{m_{d}^{2}+m_{q}^{2}}$, where $m_{d}$ and $m_{q}$ values represent the $d q$ motor current components normalized with respect to the DC Link current. After an inverse Park transformation, the normalized $m_{\alpha}$ and $m_{\beta}$ currents components are computed. Thus, the ASVM for a CSI is used to determine the interval times of the required active and zero vectors with the calculation of the modulation index $m$.

This results in a control scheme that removes the need of a front-end converter stage. This is shown in Fig. 4 which supplies the required $i_{d c}$ current. As can be observed, the whole concept is based on the CSI working in boost operation. Regulation takes place through a new closed loop control on

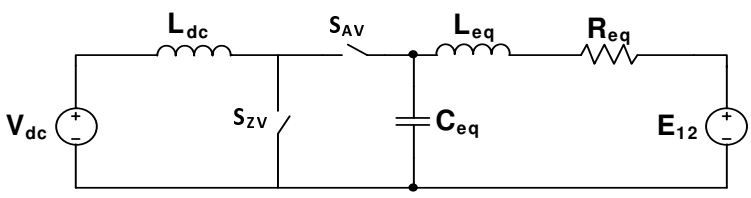

Fig. 5. Equivalent circuit of CSI converter during the application of the Zero Vector and one of the Active Vectors.

the $i_{d c}$ current. Considering the similarity between a CSI's behaviour and a Synchronous-Boost converter, such as the one shown in Fig. 5, then it can be said that the $L_{e q}, R_{e q}$ and $E_{12}$ represent the equivalent circuit of the machine during the application of one of the Active Vectors. The zero vector is implemented with $S_{Z V}$ and the active vector with $S_{A V}$. In fact, the higher output current/power can be transferred with higher values of $t_{z}$, i.e. the duty cycle of this equivalent boost converter. For this reason in Fig. 4 there is the inversion of the $i_{d c}$ current loop sign.

Eq. (1) shows the relation between $i_{d c}$ current and output current $\left|i_{r e f}\right|$ under the hypothesis that $i_{d c}$ current is in Continuous Conduction Mode (CCM). The CCM condition is the fundamental property that guarantees the stability analysis provided in the next section.

When a CSI is used in motor drive application, the output filter swaps reactive power with the motor. To reduce this effect an additional control loop on the $i_{d}$ current is implemented to exchange reactive power with the inverter.

The external loop is closed on the electrical speed $\omega_{e}$. The output of the regulation between the reference $\omega_{e}^{\star}$ and $\omega_{e}$ measured represents the reference $i_{d c}^{\star}$ value. The values of the PI regulators in Fig. 4 are chosen in accordance with the Nyquist synthesis.

The times of the active and zero states are calculated with (4). This control thus determines the $i_{d c}$ value in relation to the load.

The proposed control allows to manage the $i_{d c}$ imposing CCM operations without the use of a front-end converter 
TABLE I

STATE SPACE EQUATIONS OF THE CSI FOR ONE SECTOR UNDER CCM CONDITION

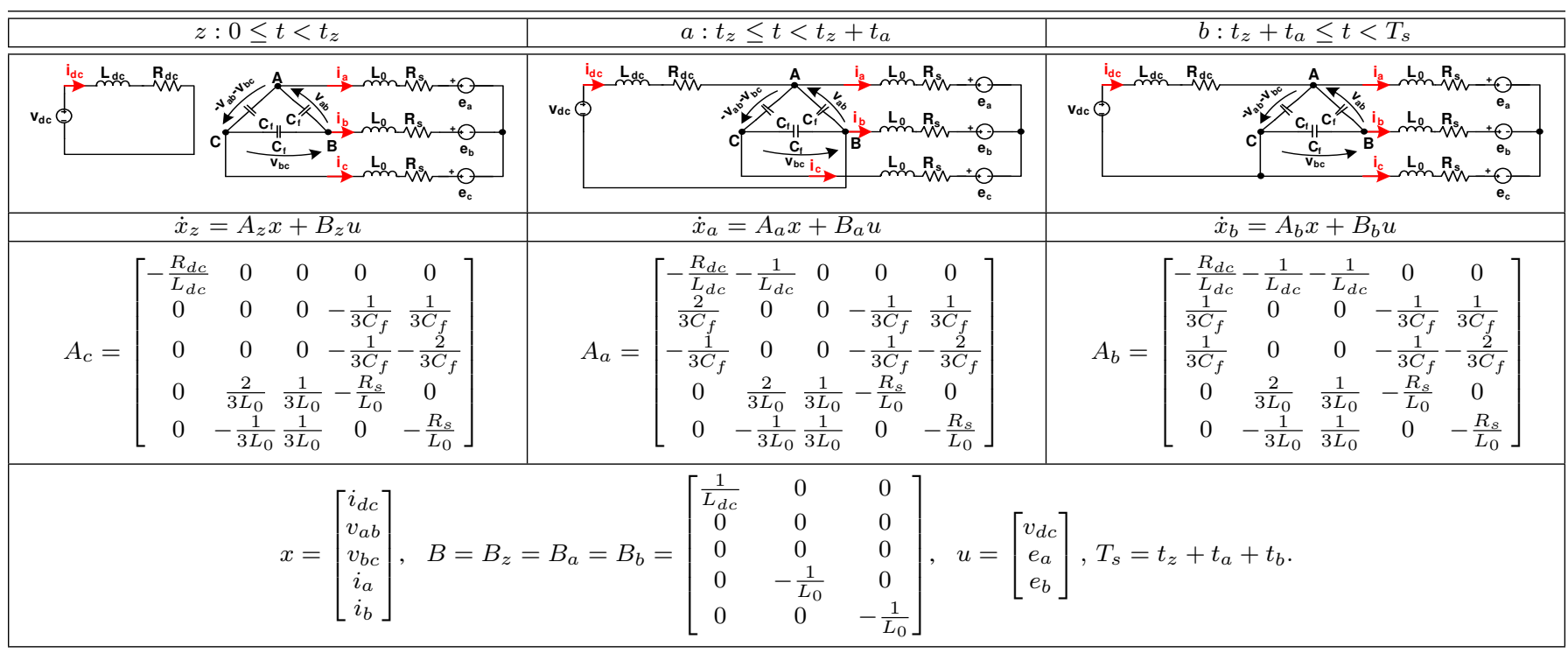

regulating this current. Without the use of the additional frontend converter there is an intrinsic bond determined by the input-output voltage relationship of the boost converter.

This load-adaptive control of the inductor current effectively reduces the losses at partial load respect to the use of a frontend converter regulating constant DC current. This will be shown through simulations in Section V.

\section{Stability ANALYSIS AND ROBUSTNESS}

Stability analysis of the CSI converter is addressed following the processes in [24] for a phasor-PWM-based CSI connected to a resistive-inductive load, in [25] for a single phase CSI and in [26] for a CSI converter feeding a PMSM with a front-end converter stage and an LC filter. In Table I $L_{d c}$ and $R_{d c}$ represent the DC-link inductor and resistor, $C_{f}$ represent the ac-side filter capacitor, $i_{d c}, v_{d c}, i_{a}, i_{b}, v_{a b}$ and $v_{b c}$ represent the DC-link current and voltage, inverter-side current and voltage, respectively. Considering the schemes shown in Table 1 and using the average method [27], [28], [29], the large signal model can be derived for one sector. The state vector $x$ is given by $\left[i_{d c}, v_{a b}, v_{b c}, i_{a}, i_{b}\right]^{T}$, because $v_{c a}$ and $i_{c}$ can be written in terms of $v_{a b}, v_{b c}$ and $i_{a}, i_{b}$, respectively.

The back emf terms $e_{a}, e_{b}$ and $e_{c}$ are considered as inputs of the system.

There are six distinct state space models, one for each sector (see Fig. 2), but the averaged matrices obtained for all the sectors in the $d q$-reference frame are the same [24] so it is enough to consider only a single sector of the modulation.

In the following subsections the large signal and the small signal models are derived in $d q$ reference frame. To study the stability of the linearized model, the small signal model is studied in an equilibrium point $x_{e}$.

\section{A. Large-signal model}

The average representation of state matrix $A$ in three phase for a CSI feeding a PMSM results in

$$
\bar{A}=\left[d_{z} A_{z}+d_{a} A_{a}+d_{b} A_{b}\right]
$$

and in the $d q$ rotating frame (obtained using Clarke and Park transformations) the average model can be written as

$$
\begin{aligned}
\frac{d}{d t}\left[\begin{array}{c}
i_{d c} \\
v_{d} \\
v_{q} \\
i_{d} \\
i_{q}
\end{array}\right] & =\overbrace{\left[\begin{array}{ccccc}
-\frac{R_{d c}}{L_{d c}}-\frac{\sqrt{3}}{2 L_{d c}} m-\frac{1}{2 L_{d c}} m & 0 & 0 \\
\frac{\sqrt{3}}{3 C_{f}} m & 0 & \omega_{e} & -\frac{1}{2 C_{f}} & \frac{\sqrt{3}}{6 C_{f}} \\
\frac{1}{3 C_{f}} m & -\omega_{e} & 0 & -\frac{\sqrt{3}}{6 C_{f}}-\frac{1}{2 C_{f}} \\
0 & \frac{1}{2 L_{0}} & \frac{\sqrt{3}}{6 L_{0}} & -\frac{R_{s}}{L_{0}} & 0 \\
0 & -\frac{\sqrt{3}}{6 L_{0}} & \frac{1}{2 L_{0}} & 0 & -\frac{R_{s}}{L_{0}}
\end{array}\right]}^{\bar{A}}\left[\begin{array}{c}
i_{d c} \\
v_{d} \\
v_{q} \\
i_{d} \\
i_{q}
\end{array}\right] \\
+ & {\left[\begin{array}{ccc}
\frac{1}{L_{d c}} & 0 & 0 \\
0 & 0 & 0 \\
0 & 0 & 0 \\
0 & -\frac{1}{L_{0}} & 0 \\
0 & 0 & -\frac{1}{L_{0}}
\end{array}\right]\left[\begin{array}{c}
v_{d c} \\
e_{d} \\
e_{q}
\end{array}\right] . }
\end{aligned}
$$

\section{B. Small-signal model}

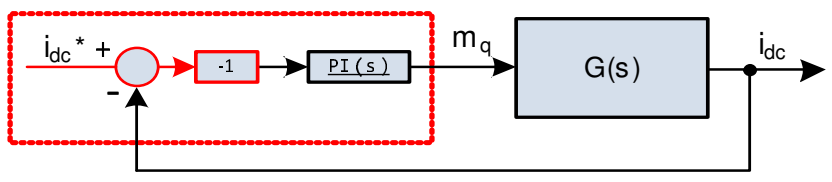

Fig. 6. Control scheme considered for the stability of the equilibrium point.

In this Section, the small-signal model of the three-phase CSI connected to a PMSM is derived.

In (6) $v_{d c}$ represents the system input for constant values of $m$ and $\omega$, but in practice, $m$ is used to regulate the output of the 


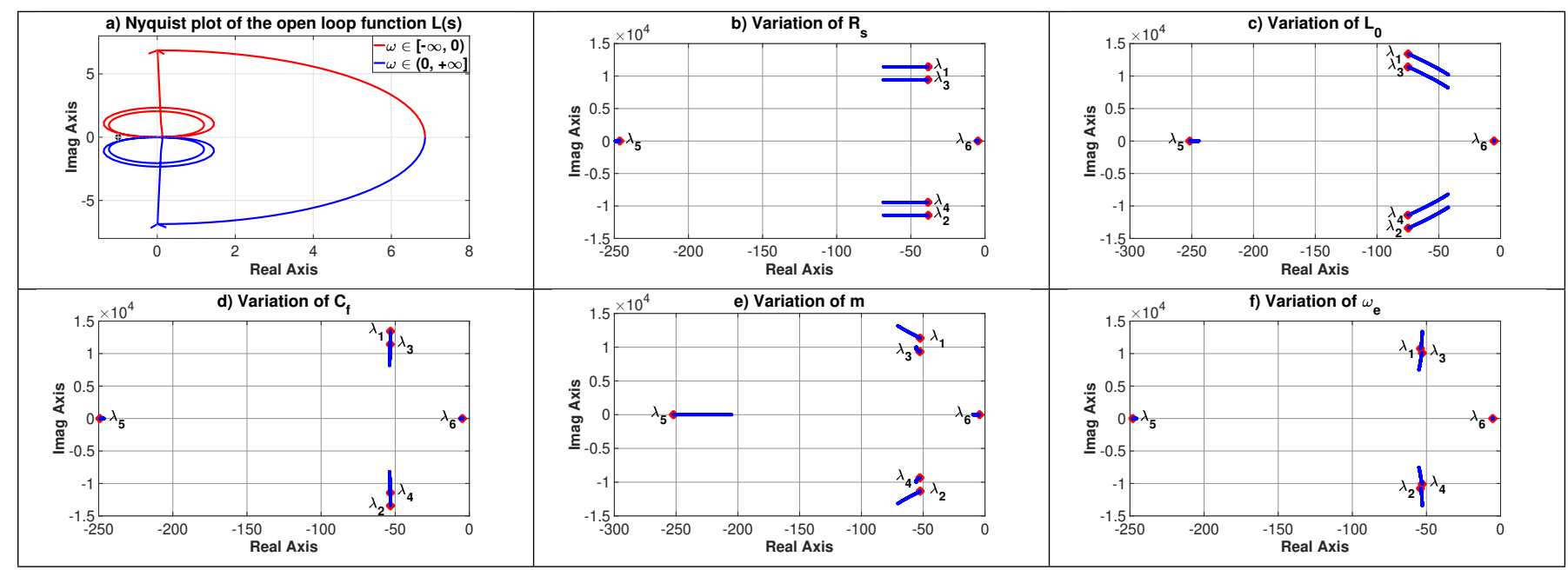

Fig. 7. a) is the Nyquist plot of the open loop function $L(s)$. b), c), d) are the eigenvalues of the closed loop against variations of $R_{s}, L_{0}$ and $C_{f}$ between $-30 \%$ and $30 \%$. e), f) are the eigenvalues of $m$ and $\omega_{e}$ between 0.1 and $\sqrt{3} / 2$ and 300 and $3000 \mathrm{rad} / \mathrm{s}$, respectively. The red symbol represents the lower bound of each plot.

current source inverter. This results in the large signal model (6) to be linearized around a steady-state operating point by defining small perturbations as

$$
\begin{aligned}
x_{d q} & =X_{d q}+\delta x_{d q} \\
v_{d c} & =V_{d c}+\delta v_{d c} \\
m & =M+\delta m \\
\omega_{e} & =\Omega_{e}+\delta \omega_{e}
\end{aligned}
$$

Also, the back emf terms $e_{d}$ and $e_{q}$ are substituted by

$$
\begin{aligned}
& e_{d}=L_{0} \omega_{e} i_{q} \\
& e_{q}=-L_{0} \omega_{e} i_{d}-\omega_{e} \lambda_{P M}
\end{aligned}
$$

The resulting linearized small-signal model is therefore as given by (9).

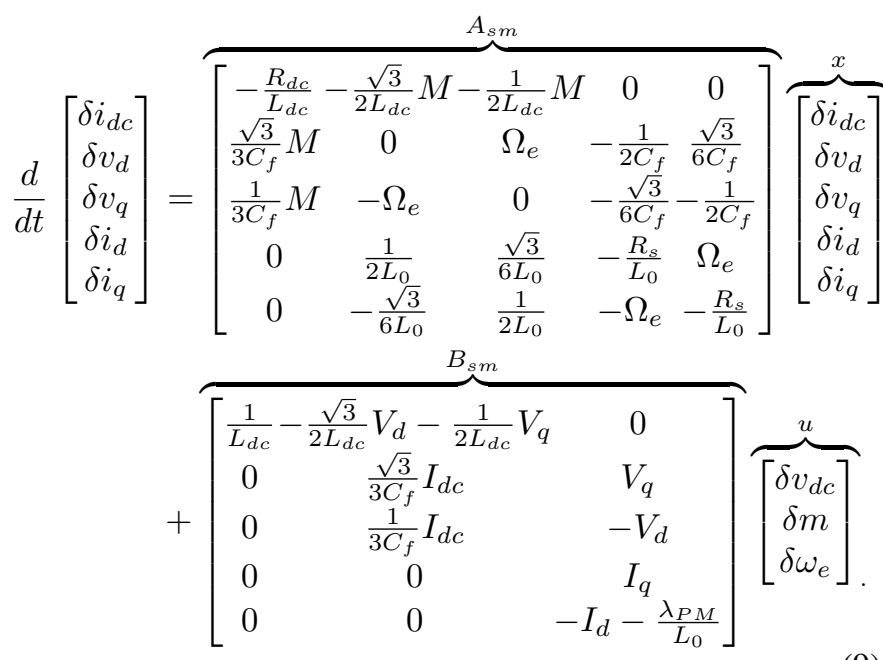

The closed loop control that regulates the error between the reference current $i_{d c}^{\star}$ and the measured $i_{d c}$ with a proportional-integral controller which assure the regulation of the error (see Fig. 6), as presented above represent one of the main innovation of this paper. The stability proof is made by computing the transfer function $G(s)$ between the input $\delta m$ and the output $\delta i_{d c}$ considering the matrices $A_{s m}$ and $B_{s m}$ in (9) and the output matrix $C_{s m}$ as $[1,0,0,0,0]$ to select $\delta i_{d c}$, while the input-output matrix $D_{s m}$ is equal to zero because there is no direct connection between the input and the output.

The open loop function $L(s)$ given by $P I(s) G(s)$ presents poles in the left half plane, i.e. $\operatorname{Re}\left\{\lambda_{i}\right\}<0$. This ensures the stability of the closed loop, as it is necessary that the Nyquist diagram of $L(s)$ presents no turns around the point -1 . For the stability analysis the Nyquist criterion is preferred to a Bode diagram because the system passes the $0 \mathrm{~dB}$ axe multiple times, so the stability isn't regular but conditional. All eigenvalues of the closed loop system are located in the left-half $s$-plane, indicating an asymptotically stable system. But this does not mean that the system is stable in presence of parameters change, so variation of the eigenvalues must be studied. As shown in Fig. 7 the system remains stable in case of perturbations on the parameters $R_{s}, L_{0}, C_{f}, m$ and $\omega_{e}$.

\section{Overall system stability}

The stability of the other loops, i.e. the $i_{d}$ current and of the speed is here studied. Supposing the the $i_{d}$ current loop is perfectly decoupled, the open loop transfer function $G_{o l}^{i_{d}}(s)$ choosing for the regulation a PI - controller is given by

$$
G_{o l}^{i_{d}}(s)=\frac{K_{p}^{i_{d}} s+K_{i}^{i_{d}}}{s} \frac{1}{s L_{0}+R_{s}}
$$

obtaining the closed loop transfer function

$$
G_{c l}^{i_{d}}(s)=\frac{K_{p}^{i_{d}} s+K_{i}^{i_{d}}}{L_{0} s^{2}+\left(K_{p}^{i_{d}}+R_{s}\right) s+K_{i}^{i_{d}}}
$$

the closed loop stability is ensured choosing proper values of $K_{p}^{i_{d}}, K_{i}^{i_{d}}>0$.

Regarding the stability of the speed loop, the dynamic of the $i_{d c}$ current loop can be considered as a low pass filter

$$
G_{c l}^{i_{d c}}(s)=\frac{i_{d c}(s)}{i_{d c}^{\star}(s)}=\frac{\omega_{c c}}{s+\omega_{c c}}
$$


where $\omega_{c c}$ is the current loop bandwidth which is higher than the speed loop bandwidth. The open loop transfer function $G_{o l}^{\omega}(s)$ of the speed loop can be computed as

$$
G_{o l}^{\omega}(s)=\frac{K_{p}^{\omega} s+K_{i}^{\omega}}{s} \frac{1}{J s} \frac{\omega_{c c}}{s+\omega_{c c}}
$$

where $J$ is the inertia of the motor. The stability of the closed loop transfer function $G_{c l}^{\omega}(s)$ given by

$$
G_{c l}^{\omega}(s)=\frac{\left(K_{p}^{\omega} s+K_{i}^{\omega}\right) \omega_{c c}}{J s^{3}+J \omega_{c c} s^{2}+K_{p}^{\omega} \omega_{c c} s+K_{i}^{\omega} \omega_{c c}}
$$

is assessed by Routh criterion respecting the conditions $K_{p}^{\omega} \omega_{c c}>K_{i}^{\omega}$ and $K_{i}^{\omega} \omega_{c c}>0$.

\section{LCL resonant circuit}

Another important issue to take into consideration is the LCL resonant circuit composed by the DC inductance, the output capacitor filter and the motor inductance which is already analyzed in [30]. From the equivalent circuit listed in Table I it can be found that the dc inductor $L_{d c}$, the filter capacitor $C_{f}$, and the load inductor $L_{0}$ form an LCL resonant circuit. Computing from the small-signal model in (9) the transfer function between the input $v_{d c}$ and the output $i_{d c}$ results in (neglecting the resistances $R_{d c}$ and $R_{s}$ to evaluate the undamped scenario)

$$
\frac{i_{d c}(s)}{v_{d c}(s)}=\frac{3 C_{f} L_{0} s^{2}+1}{3 C_{f} L_{0} L_{d c} s^{3}+\left(2 M^{2} L_{0}+L_{d c}\right) s}
$$

The Bode diagram of the transfer function is shown in Fig. 8 ensuring the stability also in the worst case even with multiple crossings of the axe of the $0 \mathrm{~dB}$.

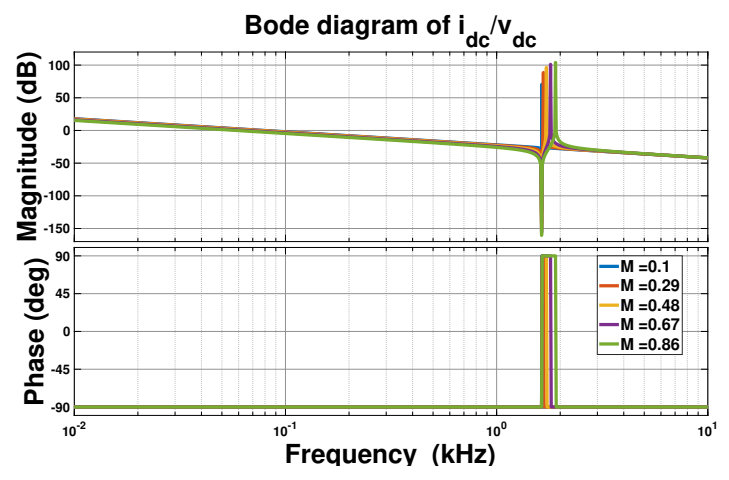

Fig. 8. Bode diagram of undamped LCL filter transfer function.

In our application, due to the resistance of the cables, capacitors and damping resistance of the LCL filter, the stability margins are even bigger as summarized in Table II.

TABLE II

STABILITY MARGINS FOR THE DAMPED LCL FILTER

\begin{tabular}{|c|c|c|}
\hline \hline M & Gain margin & Phase margin \\
\hline \hline 0.1 & $\infty$ & $120.07^{\circ}$ \\
\hline 0.29 & $\infty$ & $120.56^{\circ}$ \\
\hline 0.48 & $\infty$ & $121.54^{\circ}$ \\
\hline 0.67 & $\infty$ & $123.03^{\circ}$ \\
\hline 0.86 & $\infty$ & $125.04^{\circ}$ \\
\hline
\end{tabular}

TABLE III

Current Source InVERTER Simulation PARAmeters

\begin{tabular}{|c|c|c|}
\hline Name & Value & Unit \\
\hline \hline$v_{d c}$ & 270 & $\mathrm{~V}$ \\
\hline$i_{d c \max }$ & 140 & $\mathrm{~A}$ \\
\hline$m_{\text {qmax }}$ & 0.86 & - \\
\hline$\omega_{\text {ref }}$ & 5150 & $\mathrm{rad} / \mathrm{s}$ \\
\hline$L_{d c}$ & 2 & $\mathrm{mH}$ \\
\hline$T_{\mathrm{S}-\mathrm{AltPWM}}$ & 50 & $\mu \mathrm{s}$ \\
\hline$T_{\text {ov }}$ & 1 & $\mu \mathrm{s}$ \\
\hline$C$ & 6.6 & $\mu \mathrm{F}$ \\
\hline \multicolumn{2}{|c}{} \\
\end{tabular}

TABLE IV

PMSMS ELECTRICAL PARAMETERS

\begin{tabular}{|c|c|}
\hline \hline Parameter & Value \\
\hline \hline Phase current (rms) & $114.3 \mathrm{~A}$ \\
\hline$R_{s}$ & $0.05 \Omega$ \\
\hline$L_{0}$ & $0.48 \mathrm{mH}$ \\
\hline$k_{M}$ & $0.2392 \mathrm{Vs} / \mathrm{rad}$ \\
\hline Fundamental freq. & $833.3 \mathrm{~Hz}$ \\
\hline Torque ripple & $5.48 \%$ \\
\hline Mechanical power & $32.2 \mathrm{~kW}$ \\
\hline
\end{tabular}

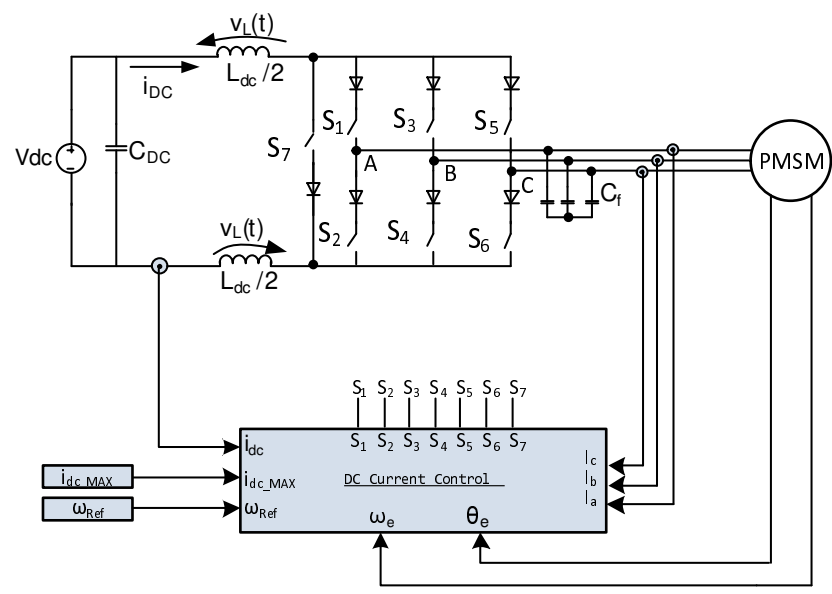

Fig. 9. Schematic of the Simulation.

\section{Simulation RESUlts}

To investigate the proposed concept, a full model of the CSI with the proposed current control is built in a Matlab/PLECS environment. The model architecture is shown in Fig.9. The main simulation parameters are reported in Table III. A PMSM machine has been considered and its parameters are reported in Table IV. Because of the intrinsic boost capability of the CSI, a high-speed machine is used as a reference for the simulation analysis.

In order to verify the correctness of the small signal model, in Fig. 10 the comparison between the $i_{d c}$ from the simulation schematic in Fig. 9 and the $i_{d c}$ from the small signal model is shown exhibiting a good approximation of the proposed model. The simulation take into consideration an open loop control imposing a $m^{\star}$ reference signal.

The proposed control is first tested with an incremental step condition. Fig. 11 plots the command condition and the ensuing results. It shows the reference and measured speed, the input current and the mechanical torque. From Fig. 11, 


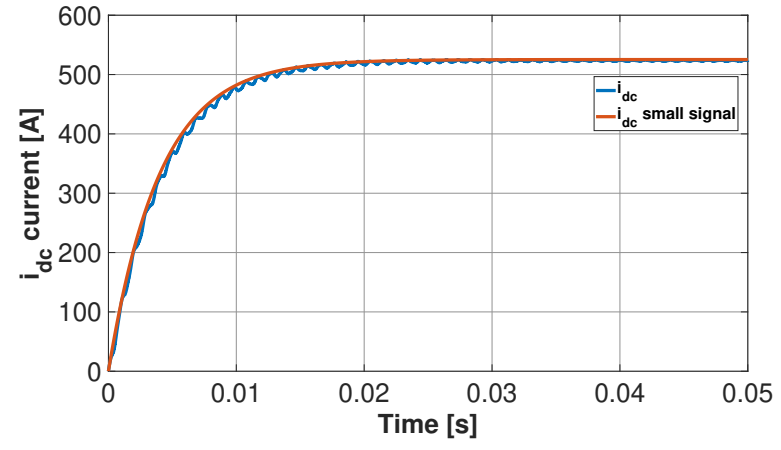

Fig. 10. Comparison between $i_{d c}$ and $i_{d c}$ of the small signal model in a open loop scenario.

the automatic adjustment of the $i_{d c}$ current in relation with the increasing load, can be easily observed. A small speed disturbance visible as an overshoot can also be observed for every load increment. However, this overshoot is immediately regulated, similar to a first order exponential transient, thus highlighting the fast and robust nature of the proposed control scheme. For these simulation tests, the maximum $i_{d c}$ is $i_{\text {dcmax }}=140 \mathrm{~A}$.
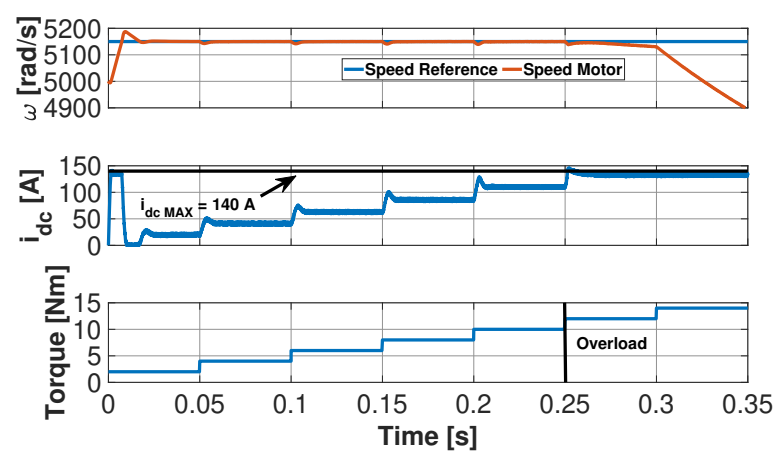

Fig. 11. Simulation: current control in normal and over-load condition.

From Fig. 11, it is also possible to observe that when the system is in overload condition (Load torque $T_{L}>10 \mathrm{Nm}$ ), the $i_{d c}$ never exceeds the $i_{d c \max }$ value. In overload condition, the speed decreases because the limit of the input current effectively acts as an electrical torque limiter, thus causing the motor speed to slow down.

From Fig. 12 it can be seen the transient response of the currents $i_{u}, i_{v}$ and $i_{w}$ during a step variation of the load torque from $4 \mathrm{Nm}$ to $6 \mathrm{Nm}$ at $0.1 \mathrm{~s}$.

Fig. 13 shows the system operation during variable speed conditions. The reference and the measured speed are shown as well as the input current. The mechanical torque indicates a constant mechanical load. Due to controller saturation, the speed rises in a linear fashion; i.e. after reaching the target speed, due to the anti-windup implemented in the PI regulators, the current is well regulated to match the increased power condition.

To fully understand the advantages of the proposed scheme, a detailed comparison of power losses between a CSI with a chopper front-end stage with a constant $i_{d c}$ current and the CSI

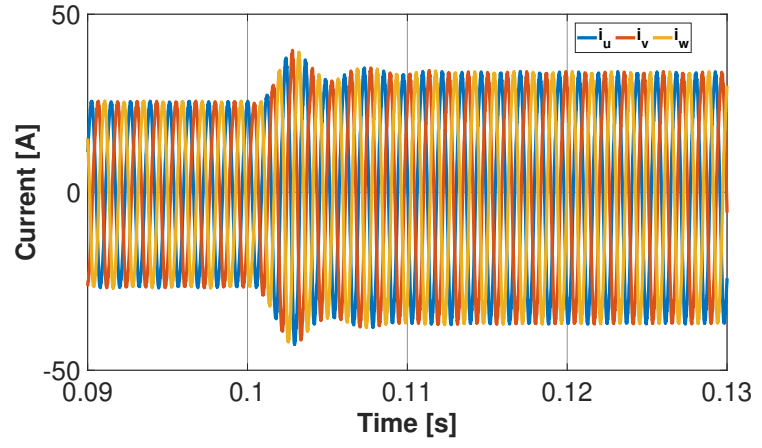

Fig. 12. Simulation: current transient during step torque from $4 \mathrm{Nm}$ to 6 $\mathrm{Nm}$.

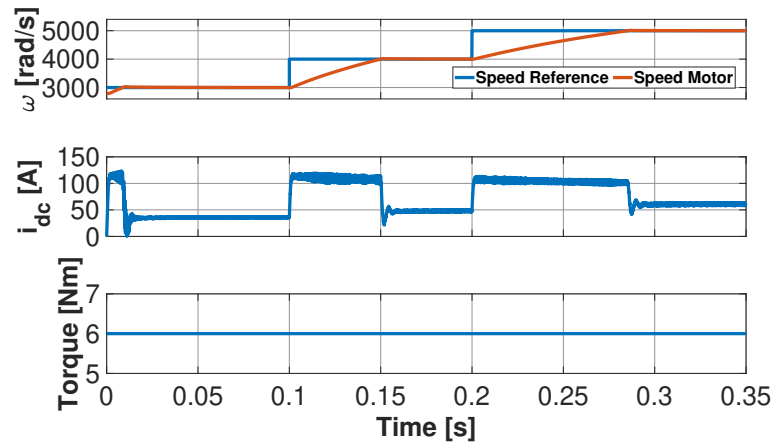

Fig. 13. Simulation: current control at different speed references.

with the proposed current control has been done. Considering that losses are highly dependant on the type of switching device technology used, then the models for each configuration were first built with Silicon IGBTs and then also with SiC MOSFETs.

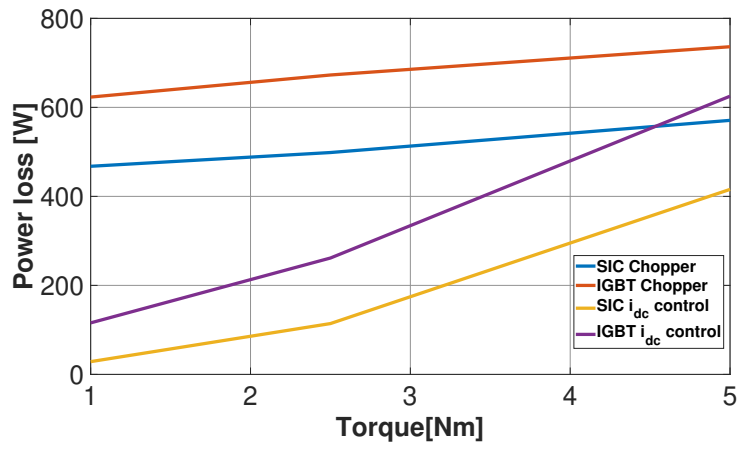

Fig. 14. Total Power losses comparison between $i_{d c}$ control and Chopper.

Thus two sets of results are achieved from both the traditional and the proposed configurations. The results are compared in Fig. 14.

The choice between these two technologies are a consequence of the $1200 \mathrm{~V}$ voltage rating. In fact, $1200 \mathrm{~V}$ Silicon MOSFETs, with an acceptable on-state resistance, are today still not commercially available. If a lower voltage rating was acceptable, the solution of Si MOSFET optimized for conduction losses (i.e., CoolMos technology without fast recovery 
body diode) could also be considered. In fact, no reverse recovery of the MOSFET body diode happens in the CSI topology. The configuration with $i_{d c}$ Current control and $\mathrm{SiC}$ devices has the lowest power losses. It should be noted, that the DC chopper would allow to operate the machine even when the back-emf is lower than the DC input voltage. The comparison of Fig. 14, therefore, is valid only when the operating speed of the machine is high enough so that the back-emf exceeds the input voltage.

\section{EXPERIMENTAL RESULTS}

To validate the proposed control scheme and thus prove that a CSI converter can be used without a pre-conditioning stage, a complete prototype of the CSI7 has been realized. The prototype system has been developed based on $\mathrm{SiC}$ devices, as used in the simulation section (Wolfspeed C2M0025120D). A commercial TMS320F2812 digital signal controller that implements the modulation strategy and the control with a sampling and switching frequency of $10 \mathrm{kHz}$ was used.

The PE is connected to a PMSM machine and a loading system as shown in Fig. 15. A machine on derated power and with limited speed is used, and an input voltage of 28 $\mathrm{V}$ as the DC bus is selected. A Digital to Analog Converter (DAC) is used to plot the internal variables of the DSP onto an oscilloscope.

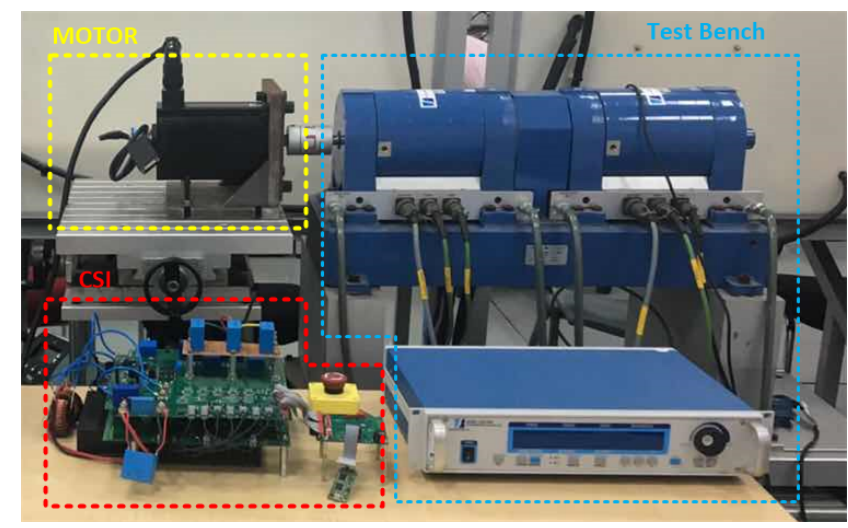

Fig. 15. CSI7 Inverter prototype with $\mathrm{SiC}$ devices and Test Bench.

Having setup the prototype and its test bench, a series of experimental runs were designed aimed to prove the concept of the proposed scheme and also investigate its stability when various operating conditions are considered. The results from these tests are then compared against those achieved from the simulation model, where the same operating conditions as those in Section $\mathrm{V}$ are recreated experimentally.

Fig. 16 shows the relevant waveform, when the CSI is driving the test machine at a constant speed. In this case, a load profile similar to Section $\mathrm{V}$ is generated with the load system. The matching to Fig. 11 is excellent. It can be observed that for an overload condition, the speed loop cannot track the reference anymore and the measured speed decreases following the mechanical dynamics. Spikes in the DAC channels are caused by disturbances in the measurement due to the switching devices and not by glitches of the control.

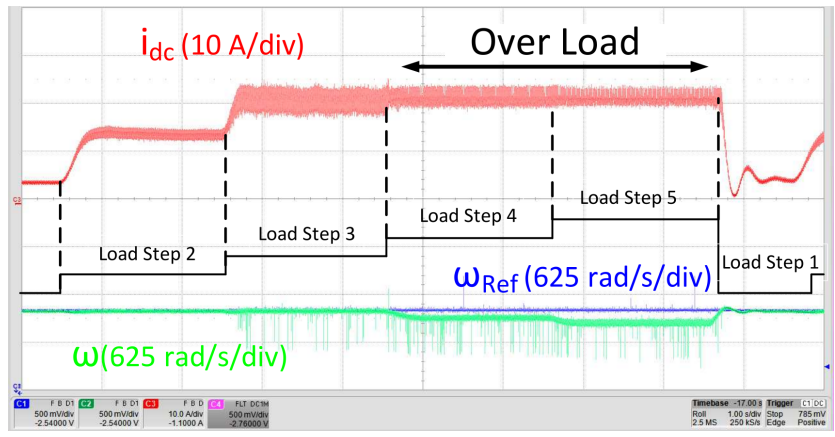

Fig. 16. Experimental results: current control in normal and over-load condition. The time division is $1 \mathrm{~s} /$ div.

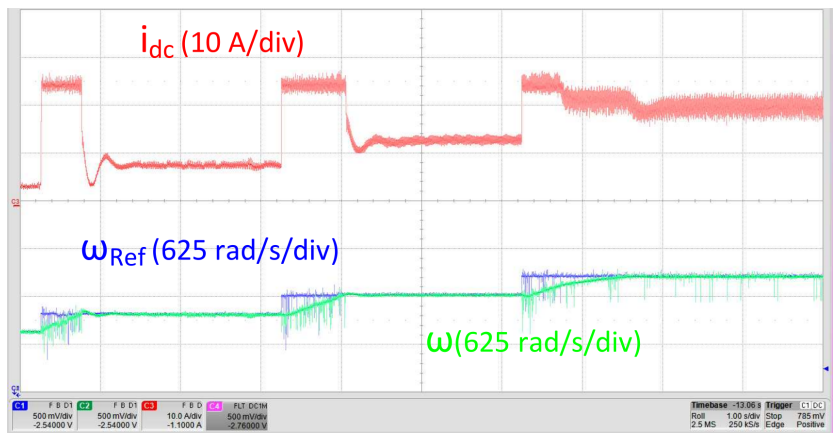

Fig. 17. Experimental results: current control with different speed references. The time division is $1 \mathrm{~s} /$ div.

Fig. 17 repeats the same condition of Fig. 13 where a speed profile is generated. The maximum speed is limited to 2500 rpm due to the bearings of the test machine. It is possible to see that the control is adapting the input current to match the load condition. The maximum input current limits the acceleration, causing the speed to increase linearly.

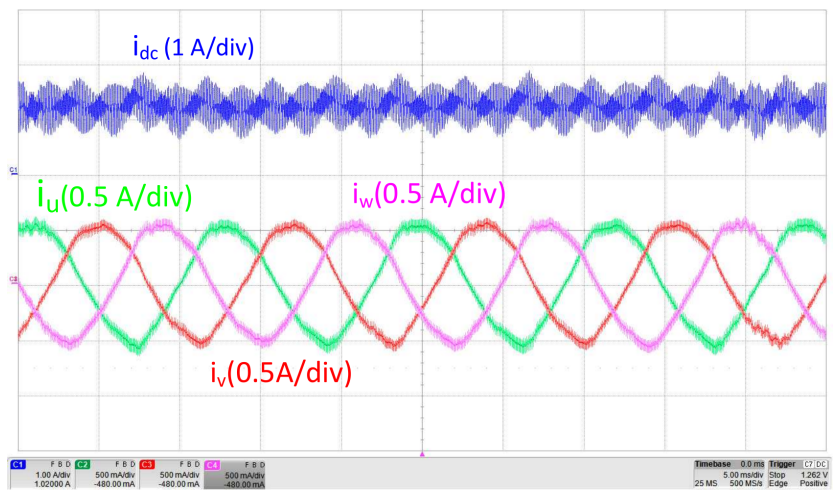

Fig. 18. Experimental results: three phase currents and $i_{d c}$ in steady - state. The time division is $5 \mathrm{~ms} / \mathrm{div}$.

Fig. 18 shows the three phase currents $i_{u}, i_{v}$ and $i_{w}$ with the DC Link current $i_{d c}$ in steady - state condition.

The distortion in the output current waveform in Fig. 18 is caused by the Alternate SVM [11] in this critical condition: low values of $i_{d c}$ and high modulation indices. The ASVM introduce a $3 \mathrm{rd}$ harmonic of the fundamental motor frequency, consequently distorting the output current. If a Base SVM is used the absence of low component frequency is ensured. 
Also using the Alternate SVM with lower modulation index would make the current distortion not noticeable. This is due to the proposed control scheme that does not need the $\mathrm{AC}$ output currents measures. The drawback of this solution is the absence of any disturbance rejection from $i_{d c}$ variation that can determines an harmonic distortion in the output currents if the $i_{d c}$ waveform presents harmonics of the fundamental motor frequency.

\section{CONCLUSION}

In this work, a novel control scheme has been proposed allowing to remove the need for the conditioning circuit at the input of a CSI for all the applications in which the electric motor has to work for almost all the time at high speed, i.e. pumps, compressors. This approach has been theoretically analyzed, simulated and experimentally validated. To investigate the performance of the CSI drive used here, a stability analysis of the CSI was conducted by deriving the average state-space model of the converter with the proof of the stability by Nyquist criterion and eigenvalues position in presence of perturbation on the most important parameters of the model. All the simulation results and proof-of-concept experiments confirm that the CSI drive can operate as a singlestate solution with intrinsic voltage boost capability. Having removed this drawback, then the inherent advantages of a CSI drive can be full exploited: boost capability, absence of electrolytic capacitors and low motor insulation stress due to the low $d V / d t$. In addiction, in this work it has also been shown how a CSI without the front-end converter can be implemented with the aim of driving a PMSM motor with low power losses thanks to the reduced number of stages and the load-dependent control. The main perceived limitation of the proposed scheme is the intrinsic boost operation, which limits the minimum speed.

\section{REFERENCES}

[1] G. Buticchi, S. Bozhko, M. Liserre, P. Wheeler, and K. Al-Haddad, "Onboard Microgrids for the More Electric Aircraft - Technology Review," IEEE Transactions on Industrial Electronics, 2019.

[2] C. Gerada, M. Galea, and A. Kladas, "Electrical Machines for Aerospace Applications," in 2015 IEEE Workshop on Electrical Machines Design, Control and Diagnosis (WEMDCD), March 2015, pp. 79-84.

[3] C. Zhao, D. Dujic, A. Mester, J. K. Steinke, M. Weiss, S. LewdeniSchmid, T. Chaudhuri, and P. Stefanutti, "Power Electronic Traction Transformer-Medium Voltage Prototype," IEEE Transactions on Industrial Electronics, vol. 61, no. 7, pp. 3257-3268, July 2014.

[4] T. Ericsen, N. Hingorani, and Y. Khersonsky, "Power electronics and Future Marine Electrical Systems," IEEE Transactions on Industry Applications, vol. 42, no. 1, pp. 155-163, Jan 2006.

[5] D. Gerada, X. Huang, C. Zhang, H. Zhang, X. Zhang, and C. Gerada, "Electrical Machines for Automotive Electrically Assisted Turbocharging," IEEE/ASME Transactions on Mechatronics, vol. 23, no. 5, pp. 2054-2065, Oct 2018.

[6] Z. Huang, T. Yang, P. Giangrande, S. Chowdhury, M. Galea, and P. Wheeler, "An Active Modulation Scheme to Boost Voltage Utilization of the Dual Converter With a Floating Bridge," IEEE Transactions on Industrial Electronics, vol. 66, no. 7, pp. 5623-5633, July 2019.

[7] G. Su and P. Ning, "Loss Modeling and Comparison of VSI and RB-IGBT Based CSI in Traction Drive Applications," in 2013 IEEE Transportation Electrification Conference and Expo (ITEC), June 2013, pp. 1-7.

[8] S. Sridharan and P. T. Krein, "Performance and Efficiency Enhancement of Induction Machine Drives: Duality-Based Approach to VSI and CSI Control," in 2013 IEEE 14th Workshop on Control and Modeling for Power Electronics (COMPEL), June 2013, pp. 1-8.
[9] B. Sahan, S. V. Araújo, C. Nöding, and P. Zacharias, "Comparative Evaluation of Three-Phase Current Source Inverters for Grid Interfacing of Distributed and Renewable Energy Systems," IEEE Transactions on Power Electronics, vol. 26, no. 8, pp. 2304-2318, Aug 2011.

[10] Y. Geng, K. Yang, Z. Lai, P. Zheng, H. Liu, and R. Deng, "A Novel Low Voltage Ride Through Control Method for Current Source GridConnected Photovoltaic Inverters," IEEE Access, vol. 7, pp. 5173551748,2019

[11] E. Lorenzani, F. Immovilli, G. Migliazza, M. Frigieri, C. Bianchini, and M. Davoli, "CSI7: A Modified Three-Phase Current-Source Inverter for Modular Photovoltaic Applications," IEEE Transactions on Industrial Electronics, vol. 64, no. 7, pp. 5449-5459, July 2017.

[12] P. Wheeler and S. Bozhko, "The More Electric Aircraft: Technology and challenges." IEEE Electrification Magazine, vol. 2, no. 4, pp. 6-12, Dec 2014.

[13] A. C. UK, "Automotive technology roadmaps: Electric machines" 2017.

[14] V. Madonna, G. Migliazza, P. Giangrande, E. Lorenzani, G. Buticchi, and M. Galea, "The Rebirth of the Current Source Inverter. Advantages for Aerospace Motor Design," IEEE Industrial Electronics Magazine, vol. 20, no. 4, pp. 1-15, Dec 2019.

[15] Y. W. Li, M. Pande, N. R. Zargari, and B. Wu, "DC-Link Current Minimization for High-Power Current-Source Motor Drives," IEEE Transactions on Power Electronics, vol. 24, no. 1, pp. 232-240, 2009.

[16] H.-C. Chen and H.-H. Huang, "Design of buck-type current source inverter fed brushless DC motor drive and its application to position sensorless control with square-wave current," IET Electric Power Applications, vol. 7, no. 5, pp. 416-426, 2013.

[17] P. C. Loh, P. C. Tan, F. Blaabjerg, and T. K. Lee, "Topological Development and Operational Analysis of Buck-Boost Current Source Inverters for Energy Conversion Applications," in 2006 37th IEEE Power Electronics Specialists Conference, June 2006, pp. 1-6.

[18] Z. Wu and G.-J. Su, "High-Performance Permanent Magnet Machine Drive for Electric Vehicle Applications Using a Current Source Inverter," in 2008 34th Annual Conference of IEEE Industrial Electronics. IEEE, 2008, pp. 2812-2817.

[19] A. Bendre, I. Wallace, J. Nord, and G. Venkataramanan, "A Current Source PWM Inverter with Actively Commutated SCRs," IEEE Transactions on Power Electronics, vol. 17, no. 4, pp. 461-468, July 2002.

[20] D. N. Zmood and D. G. Holmes, "A Generalised Approach to the Modulation of Current Source Inverters," in PESC 98 Record. 29th Annual IEEE Power Electronics Specialists Conference (Cat. No.98CH36196), vol. 1, May 1998, pp. 739-745 vol.1.

[21] B. Wu and M. Narimani, High-power converters and AC drives. John Wiley \& Sons, 2017, vol. 59.

[22] G. Buticchi, S. Bozhko, M. Liserre, P. Wheeler, and K. Al-Haddad, "OnBoard Microgrids for the More Electric Aircraft-Technology Review," IEEE Transactions on Industrial Electronics, vol. 66, no. 7, pp. 55885599, July 2019.

[23] V. Madonna, P. Giangrande, and M. Galea, "Electrical Power Generation in Aircraft: Review, Challenges, and Opportunities," IEEE Transactions on Transportation Electrification, vol. 4, no. 3, pp. 646-659, Sep. 2018.

[24] A. Singh, A. K. Kaviani, and B. Mirafzal, "On Dynamic Models and Stability Analysis of Three-Phase Phasor PWM-Based CSI for Stand-Alone Applications," IEEE Transactions on Industrial Electronics, vol. 62 , no. 5, pp. 2698-2707, May 2015.

[25] H. Komurcugil, "Steady-State Analysis and Passivity-Based Control of Single-Phase PWM Current-Source Inverters," IEEE Transactions on Industrial Electronics, vol. 57, no. 3, pp. 1026-1030, March 2010.

[26] H. Lee, S. Jung, and S. Sul, "A Current Controller Design for Current Source Inverter-Fed AC Machine Drive System," IEEE Transactions on Power Electronics, vol. 28, no. 3, pp. 1366-1381, March 2013.

[27] J. A. Sanders, F. Verhulst, and J. A. Murdock, Averaging methods in nonlinear dynamical systems. Springer, 2007, vol. 59.

[28] P. T. Krein, J. Bentsman, R. M. Bass, and B. L. Lesieutre, "On the Use of Averaging for the Analysis of Power Electronic Systems," IEEE Transactions on Power Electronics, vol. 5, no. 2, pp. 182-190, April 1990.

[29] S. R. Sanders, J. M. Noworolski, X. Z. Liu, and G. C. Verghese, "Generalized Averaging Method for Power Conversion Circuits," IEEE Transactions on Power Electronics, vol. 6, no. 2, pp. 251-259, April 1991.

[30] Y. Zhang and Y. W. Li, "Investigation and Suppression of Harmonics Interaction in High-Power PWM Current-Source Motor Drives," IEEE Transactions on Power Electronics, vol. 30, no. 2, pp. 668-679, Feb 2015. 


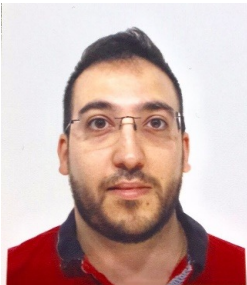

Giovanni Migliazza received the Master degree in Mechatronic Engineering and the PhD Degree in Industrial Innovation Engineering from the University of Modena and Reggio Emilia, Italy, in 2014 and 2020, respectively. He is currently a Senior Researcher Fellow at University of Modena and Reggio Emilia, Italy. He has been a visiting researcher at the University of Nottingham Ningbo China in 2019. His research interests include power electronics, converters, and electric drives. He has and one industrial patent. authored/co-authored more than 10 scientific papers

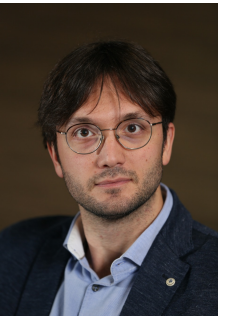

Giampaolo Buticchi received the Master degree in Electronic Engineering in 2009 and the Ph.D degree in Information Technologies in 2013 from the University of Parma, Italy. In 2012 he was visiting researcher at The University of Nottingham, UK Between 2014 and 2017, he was a post-doctoral researcher, and Guest Professor at the University of Kiel, Germany. During his stay in Germany, he was awarded with the Von Humboldt Post-doctoral Fellowship to carry out research related to fault tolerant topologies of smart transformers. In 2017 he was appointed as Associate Professor in Electrical Engineering at The University of Nottingham Ningbo China and as Head of Power Electronics of the Nottingham Electrification Center. He was promoted to Professor in 2020. His research focuses on power electronics for renewable energy systems, smart transformer fed micro-grids and dc grids for the More Electric Aircraft. Dr Buticchi is one of the advocates for DC distribution systems and multi-port power electronics onboard the future aircraft. He is author/co-author of more than 210 scientific papers and an Associate Editor of the IEEE Transactions on Industrial Electronics, the IEEE Transactions on Transportation Electrification and the IEEE Open Journal of the Industrial Electronics Society. He is currently the Chair of the IEEE Industrial Electronics Society Technical Committee on Renewable Energy Systems.

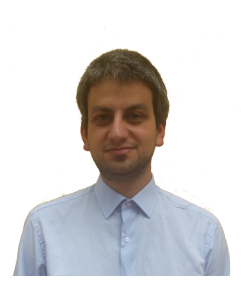

Emilio Carfagna (S'19) was born in Frosinone, Italy, in 1992. He received his Master Degree in Automation Engineering in 2018 from the University of Rome Tor Vergata, Rome, Italy. He is currently working toward the Ph.D. degree with the Electric Drives and Power Electronics Group at the University of Modena and Reggio Emilia, Reggio Emilia. His research interests are mainly focused on sensorless control design for electrical drives and industrial applications.

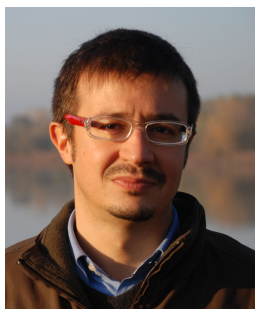

Emilio Lorenzani (S'03, M'07, SM'18) was born in Parma, Italy, in 1976. He received the M.S. degree in electronic engineering and the Ph.D. degree in information technologies from the University of Parma, Italy, in 2002 and 2006, respectively. Since 2011, he has been with the Department of Science and Engineering Methods, University of Modena and Reggio Emilia, where he is currently an Associate Professor of electric machines and drives. He is the author or coauthor of more than 70 technical papers. He holds five industrial patents and serves as Associate Editor for IET Power Electronics. His research interests include power electronics for renewable energy resources, electric drives, and electric motor diagnostics.

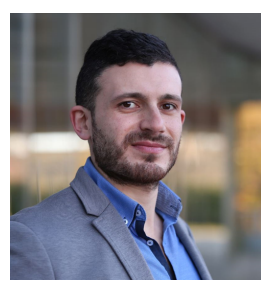

Vincenzo Madonna (M'17) received the Laurea Magistrale Degree in Electrical Engineering from the University of Bologna, Italy, in 2016, and the $\mathrm{PhD}$ Degree in Electrical Machines Design from the University of Nottingham, UK, in 2020. In 2016, he joined the Institute for Aerospace Technology at the University of Nottingham, UK as a Marie Skłodowska-Curie Doctoral Fellow in reliabilityoriented design of electrical machines for transportation. Throughout 2018, he was a Research Associate and Teaching Assistant with the Key Laboratory of More Electric Aircraft of Zhejiang Province, Ningbo, China. He is currently a Research Fellow with the Propulsion Futures Beacon of Excellence at the University of Nottingham, UK. His research interests include design, thermal management and lifetime prediction modelling of electrical machines.

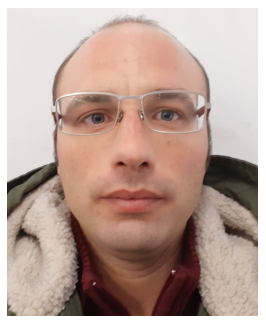

Paolo Giangrande (M'12-SM'19) received the Bachelor's (Hons.) and Master's (Hons.) degrees in electrical engineering at the Politecnico of Bari in 2005 and 2008, respectively. He received his $\mathrm{PhD}$ in electrical engineering at the Politecnico of Bari in 2011. Since 2012, he was Research Fellow at the University of Nottingham (UK), within the Power Electronics, Machines and Control Group. In 2018, he was appointed Senior Research Fellow and he is currently head of the Accelerated Lifetime Testing Laboratory at the Institute of Aerospace Technology, Nottingham. His main research interests include sensorless control of AC electric drives, design and testing of electromechanical actuators for aerospace, thermal management of high-performance electric drives and lifetime modelling of electrical machines.

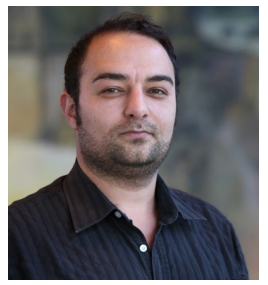

Micheal Galea received the Ph.D. degree in electrical machines design in 2013 from the University of Nottingham, Nottingham, U.K. He was appointed as Lecturer in 2014, as Associate Professor in 2018 and as Professor in Electrical Machines and Drives in 2019, all with the University of Nottingham. He currently lectures in Electrical Machines and Drives and in Aerospace Systems Integration and manages a number of diverse projects and programmes related to the more/all electric aircraft, electrified propulsion, and associated fields. His main research interests include design and development of electrical machines and drives (classical and unconventional), reliability and lifetime degradation of electrical machines and the more electric aircraft. Michael is a Fellow of the Royal Aeronautical Society and a Senior Member of the IEEE. Michael also serves an Associate Editor for the IEEE Transactions on Industrial Electronics and for the IET Electrical Systems in Transportation. 